\title{
Joint Modeling in Detecting Predictors of Cd4 Cell Count and Status of Tuberculosis Among HIV Infected Patients Under HAART at Felege Hiwot Teaching and Specialized Hospital, North-west Ethiopia
}

Setegn Byabil Agegn ( $\sim$ setegnbayabil@gmail.com )

Department of Statistics, Debre Tabor University, Debre-Tabor, Ethiopia

Awoke seyoum Tegegn

Department of Statistics, Bahir Dar University, Bahir Dar, Ethiopia

Research

Keywords: CD4 cell, TB status, Separate Model, Joint Model, HAART

Posted Date: October 14th, 2020

DOI: https://doi.org/10.21203/rs.3.rs-89429/v1

License: (c) (1) This work is licensed under a Creative Commons Attribution 4.0 International License.

Read Full License 


\section{Abstract}

Background: Globally, the number of TB patients who had been diagnosed with HIV status reached 2.1 million, which is equivalent to $34 \%$ of notified cases of TB. This research was conducted with the objective to identify potential predictors for the status of TB and CD4 cell count for adult HIV patients at Felege Hiwot Teaching and Specialized Hospital North-west Ethiopia.

Methods: A retrospective repeated measures were taken from a sample of 226 HIV patients. Separate and joint models were conducted for data analysis of CD4 cell count and TB status of HIV infected patients.

Results: The descriptive statistics indicates that among the HIV patients under HAART, $26.6 \%$ had additional TB cases. Hence, the expected number of CD4 cell count of HIV patients who were co-infected with TB was decreased by 2.34 as compared to HIV patients who were free from TB. In joint analysis, age, opportunistic infectious disease, adherence to medication, body mass index and social supports were significantly associated with CD 4 cell count and TB status. In addition, one-way interaction terms (time * educational level) was also associated with both outcomes. As patients' age increased by one year, the expected number of CD 4 cell count was decreased by 0.025 cells per $/ \mathrm{mm} 3$ keeping the other variables constant. The expected number of CD4 cell count for patients whose status were ambulatory was decreased by 3.95 as compared to working status.

Both separate and joint modeling approach revealed consistent results for significant predictors. However, joint models were more adequate and efficient.

Conclusions: Among the predictors of CD 4 cell count and TB status, WHO stages, age of patients, functional status of patients, hemoglobin level and residence area were significant predictors for the variable of interests. More attention should be given for HIV/TB co- infected ambulatory and bedridden patients.

\section{Background}

Currently, the number of TB patients who had been diagnosed with HIV status reached 2.1 million in 2010 which is equivalent to $34 \%$ of notified cases of TB in the world. About one third of 39.5 million HIV infected people worldwide were co-infected with TB [1] and up to $50 \%$ of individuals living with HIV are expected to develop TB. For individuals infected with HIV, the presence of other infections including TB tends to increase the rate of HIV replication. This acceleration may result in higher levels of infection and rapid HIV progression to the AIDS stage [2]. Of the 8.8 million TB incident cases worldwide, an estimated 1.1 million (13\%) were found to be co-infected with HIV[3].

East and Southern Africa is the hardest region hit by the HIV. This region is a home to $6.2 \%$ of the world's population and about 19.4 million people are living with the virus[4]. 
Ethiopia is one of the few African countries with the highest number of people living with HIV/AIDS. The country has 786,040 people living with HIV and 28,650 HIV/AIDS deaths [5]. Tuberculosis was the cause of 76,000 deaths in Ethiopia, out of which $30 \%$ were among HIV + patients[6]. Besides to the rate of mortality, the co-infection of HIV and TB had negative impact on the quality of livelihood system and resulting mental disorders [7]. The country is one of the 22 high burden countries with TB which accounts for an estimated annual incidence of 379 per 100,1000 population and prevalence of 643 cases per 100,000 populations [8]. The prevalence of HIV among TB patients was estimated as high as $41 \%[9,10]$. CD4 cell count is one of the most repeatedly measured variables for people living with HIV and it is used as an indicator of disease progression [11].

HIV and Tuberculosis have been closely linked since, the emergence of AIDS and TB is the most common infectious disease affecting HIV positive individuals and causing to their death.

Currently, HIV and TB treatments are common in many societies and the use of drugs has altered the joint dynamics of both diseases. Many individuals who were infected with HIV are 30-50 times more likely to develop active TB than those without HIV[11].

In many medical cases, more than one clinical outcome is measured longitudinally at the same time on the same subject where, such outcomes are correlated to each other. In such cases the univariate longitudinal analysis does not take into account correlation between observations on different response variables at each time points.

While joint models of longitudinal and time to event data are widely presented in different literatures, there is scarcity of researches conducted jointly for two longitudinal outcomes of similar or different in nature. This study was undertaken with the objective to identify common socio-demographic, clinical and economic variables affecting the CD4 cell count and status of TB under HAART for HIV/TB co- infected patients at Felege Hiwot Teaching and specialized Hospital, North-West Ethiopia.

\section{Methods}

\section{Study design}

The data used under current investigation consists of secondary data and a prospective longitudinal study design was employed.

\section{Study area and Population}

The study was conducted in Amhara region, North-west Ethiopia (Felege Hiwot Teaching and Specialized Hospital). The study was conducted on 226 HIV positive adults who initiated their treatment.

\section{Sample size and sampling procedure}

Cochran's formula was applied for determining sample size in current investigation. A total of 1574 PLWHIV were under treatment in the hospital and of these, 956(60.7\%) were under HAART. Random 
samples of $226 \mathrm{HIV}$ patients were included under current investigation. The samples were selected using stratified random sampling technique, considering their residence as strata. In sample size calculation, the possible missing records/values (for patients who had no full information) were considered and to compensate such data, $5 \%$ of the total size $\mathrm{n}$ was added. The data analyzed in the current investigation consists of a retrospective evaluation of patients' record in the hospital whose follow-ups were between September 2012 and August 2017.

\section{Variables under investigation}

\section{Response variables}

The two outcome variables considered for this study were the longitudinal measure of CD4 cell count and the status of tuberculosis (TB) for HIV patients under HAART.

Explanatory Variables: Covariates associated with CD4 count and status of tuberculosis were sex (male, female), residence area (urban, rural), level of education (no education, primary, secondary and tertiary), ownership of cell phone(yes, no), marital status (living with partner, living without partner), level of income (low, middle and high), WHO stages (stage1, stage2, stage3 and stage4), whether or not the patient disclosed the disease (yes, no), age in years, and baseline CD4 cells count in cells/mm3, medication adherence(adherent, not adherent), diet adherence (adherent, non-adhered), body mass index, WHO clinical stages, Functional status, Hemoglobin level, opportunistic infectious disease, social support (yes, no).

\section{Inclusion Criteria}

Patients whose age was above 18 years and attended a minimum of two follow up visits of HAART treatment in ART clinic for refilling their prescription, and who were initiated their HAART in 1st January 2015 to 31 st December 2018 at Felege Hiwot Teaching and Specialized Hospital were included in the study.

\section{Statistical Models}

A standard modeling framework for the analysis of longitudinal data is the mixed-effects model. A mixed model is one that contains both fixed and random effects. The fixed effects represents the mean response, while the random effects represents the individual level responses $[12,13]$.

In this study before construction of the joint modeling, appropriate longitudinal separate models were employed to identify the covariates that have significant effect on the expected number of the variables of interest. The reason for doing this was to compare the separate and joint models of longitudinal response variables. To identify the appropriate covariance structure, potential covariance structures were considered.

Results 
Descriptive statistics were used to summarize baseline characteristics of participants in the study area. The baseline characteristics of respondents were summarized as indicated in Table1.

Table1 indicated that out of a sample of 226 patients, $80.1 \%$ were females, $70.4 \%$ of the infected patients were with working functional status, (i.e., an individual able to perform usual work in and out of the house), and $6.6 \%$ were unable to perform activities (bedridden patients). Regarding the clinical stage of patients, $36.3 \%$ were at clinical stage $1,30.1 \%$ at clinical stage2, and $23.0 \%$ at clinical stage 3 .

Among the patients, $92.9 \%$ were adherent to the prescribed medication and the rest were non-adherent, $60.6 \%$ were from rural area, $59.7 \%$ patients were free from opportunistic infectious disease. The body mass index of patients revealed that $58 \%$ were at normal level, $28.3 \%$ at underweight, and others were overweight level, $28.8 \%$ of them were unemployment status. Among the HIV positive patients included under current investigation, $26.6 \%$ had also TB.

At enrolment, the average (std.dev) baseline age of study participants was 33.15(7.79) years. The average (Std.dev) baseline weight was $53.19(9.55) \mathrm{kg}$ and average (Std.dev) baseline hemoglobin was 11.73 (2.46). Finally, the average (Std.dev) of baseline CD4 cell count was 363.38(227.68) cells per mm3.

Among the different covariance structures, UN had smallest AIC and BIC and selected for data analysis in current investigation.

Table1: Baseline characteristics of potential predictors for HIV/AIDS patients 


\begin{tabular}{|c|c|c|c|c|c|}
\hline \multirow[t]{2}{*}{ Characteristics } & \multirow[t]{2}{*}{ Category } & \multicolumn{2}{|c|}{ TB Status } & \multirow[t]{2}{*}{ Mean CD4 cell count } & \multirow[t]{2}{*}{ Percent } \\
\hline & & Yes & No & & \\
\hline \multirow[t]{2}{*}{ Sex } & Male & 15 & 30 & 327.07 & 19.9 \\
\hline & Female & 38 & 143 & 372.42 & 80.1 \\
\hline \multirow[t]{5}{*}{ Marital status } & Single & 15 & 33 & 378.64 & 21.2 \\
\hline & Married & 21 & 86 & 393.21 & 47.3 \\
\hline & Separated & 2 & 14 & 297.35 & 7.2 \\
\hline & Divorced & 11 & 29 & 309.57 & 17.7 \\
\hline & Widow & 4 & 11 & 315.80 & 6.6 \\
\hline \multirow[t]{2}{*}{ Residence area } & Urban & 12 & 77 & 381.24 & 39.4 \\
\hline & Rural & 41 & 95 & 351.79 & 60.6 \\
\hline \multirow[t]{4}{*}{ Educational level } & No education & 21 & 49 & 416.92 & 31.0 \\
\hline & primary & 11 & 47 & 379.42 & 25.7 \\
\hline & secondary & 14 & 42 & 305.62 & 24.8 \\
\hline & Tertiary & 7 & 35 & 335.62 & 18.5 \\
\hline \multirow[t]{3}{*}{ Religion } & Muslim & 35 & 62 & 383.98 & 42.9 \\
\hline & Orthodox & 14 & 100 & 360.28 & 50.4 \\
\hline & Others & 4 & 11 & 253.79 & 6.6 \\
\hline \multirow[t]{3}{*}{ Occupation } & unemployed & 17 & 49 & 388.59 & 28.8 \\
\hline & employed & 23 & 73 & 334.93 & 42.5 \\
\hline & others & 14 & 51 & 379.89 & 28.7 \\
\hline \multirow[t]{4}{*}{ Functional status } & Ambulatory & 4 & 12 & 194.49 & 7.1 \\
\hline & Bedridden & 6 & 9 & 135.68 & 6.6 \\
\hline & working & 123 & 36 & 401.26 & 70.4 \\
\hline & Others & 7 & 29 & 366.57 & 15.9 \\
\hline \multirow[t]{2}{*}{ Opportunistic infectious } & No & 38 & 97 & 391.12 & 59.7 \\
\hline & Yes & 15 & 76 & 322.24 & 40.3 \\
\hline
\end{tabular}




\begin{tabular}{|c|c|c|c|c|c|}
\hline \multirow[t]{4}{*}{ WHO stages } & Stage 1 & 4 & 78 & 408.02 & 36.3 \\
\hline & Stage2 & 4 & 64 & 356.22 & 36.3 \\
\hline & Stage3 & 25 & 27 & 325.25 & 23 \\
\hline & Stage4 & 18 & 6 & 315.15 & 10.6 \\
\hline \multirow[t]{2}{*}{ Adherence status } & No & 6 & 10 & 108.32 & 7.1 \\
\hline & Yes & 46 & 164 & 383.35 & 92.9 \\
\hline \multirow[t]{3}{*}{ BMI } & Under weight & 26 & 38 & 316.4 & 28.3 \\
\hline & Normal & 25 & 106 & 366.7 & 58 \\
\hline & Overweight & 3 & 28 & 444.9 & 13.7 \\
\hline \multirow[t]{2}{*}{ Social support } & No & 28 & 81 & 444.9 & 48.2 \\
\hline & Yes & 25 & 92 & 366.75 & 51.8 \\
\hline \multirow[t]{2}{*}{ TB Status } & No & 60 & & & 26.55 \\
\hline & Yes & 166 & & & 73.45 \\
\hline Mean age(Std.dev) & $33.15(7.79)$ & & & & \\
\hline Mean weight(Std.dev) & $53.19(9.55)$ & & & & \\
\hline Mean Hemoglobin(Std. dev) & $11.73(2.46)$ & & & & \\
\hline Mean CD4 cell count(Std.dev) & $363.38(227.68)$ & & & & \\
\hline
\end{tabular}

Table2: Parameter Estimates of CD4 cell count, with (UN) covariance structure 


\begin{tabular}{|c|c|c|c|c|}
\hline Effect & Estimate & std.err & $95 \% \mathrm{Cl}$ & $\mathrm{p}$-value \\
\hline Intercept & 13.593 & 3.163 & $(7.359,19.837)$ & $<0.0001$ * \\
\hline Time(months) & 0.200 & 0.037 & $(0.177,0.273)$ & $<0.0001^{*}$ \\
\hline Age & -0.128 & 0.033 & $(-0.194,-0.063)$ & $0.0001^{*}$ \\
\hline \multicolumn{5}{|c|}{ Educational level (ref=tertiary } \\
\hline No education & 3.619 & 3.318 & $(-2.893,10.131)$ & 0.2757 \\
\hline Primary & -4.327 & 3.027 & $(-10.268,1.615)$ & 0.1533 \\
\hline Secondary & -6.712 & 3.091 & $(-12.780,-0.645)$ & 0.0302 \\
\hline \multicolumn{5}{|l|}{ Func.st. (ref=working) } \\
\hline Ambulatory & -3.053 & 0.946 & $(-4.911,-1.196)$ & $0.0013^{*}$ \\
\hline Bedridden & -3.750 & 1.077 & $(-5.863,-1.638)$ & $0.0005^{\star}$ \\
\hline \multicolumn{5}{|c|}{ Medication adherence (ref=non-adherent) } \\
\hline Adherent & 4.632 & 0.570 & $(3.514,5.751)$ & $<0.0001^{*}$ \\
\hline \multicolumn{5}{|c|}{ Dietary adherence(Ref. =no) } \\
\hline yes & 2.632 & 0.970 & $(1.514,4.751)$ & $<0.0001^{*}$ \\
\hline \multicolumn{5}{|l|}{ Social support(Ref.= no) } \\
\hline yes & 1.832 & 0.380 & $(1.314,5.651)$ & $<0.0001^{*}$ \\
\hline \multicolumn{5}{|c|}{ Ownership of Cell phone(Ref.=no) } \\
\hline yes & 1.832 & 0.380 & $(1.314,5.651)$ & $<0.0001^{*}$ \\
\hline \multicolumn{5}{|l|}{ BMI(Ref.=Normal) } \\
\hline over or under weighted) & -0.114 & 0.512 & $(-1.218,-0.891)$ & $0.0246^{*}$ \\
\hline Weight & 0.068 & 0.026 & $(0.016,0.120)$ & $0.0097 *$ \\
\hline \multicolumn{5}{|l|}{ WHO stage $($ Ref = st.4) } \\
\hline Stage 1 & 2.194 & 0.572 & $(1.071,3.317)$ & $0.0001 *$ \\
\hline Stage2 & 1.748 & 0.574 & $(0.622,2.874)$ & $0.0024 *$ \\
\hline Stage3 & 0.374 & 0.112 & $(0.155,0.593)$ & $0.0008 *$ \\
\hline Hemoglobin & 1.201 & 0.382 & $(0.451,1.952)$ & $0.0017^{*}$ \\
\hline TB (Ref=no) & & & & \\
\hline
\end{tabular}




\begin{tabular}{|c|c|c|c|c|}
\hline yes & -2.340 & 0.443 & $(-3.209,-1.471)$ & $<0.0001 *$ \\
\hline \multicolumn{5}{|c|}{ Disclosure of disease $($ Ref. $=$ no $)$} \\
\hline yes & 1.201 & 0.382 & $(0.451,1.952)$ & $0.0017^{*}$ \\
\hline \multicolumn{5}{|c|}{ Opportunistic infections(Ref.=no) } \\
\hline yes & -2.340 & 0.443 & $(-3.209,-1.471)$ & $<0.0001^{*}$ \\
\hline \multicolumn{5}{|c|}{ Sex (Ref.= female) } \\
\hline Male & -2.340 & 0.443 & $(-3.209,-1.471)$ & $<0.0001^{*}$ \\
\hline \multicolumn{5}{|c|}{ Residence area(Ref.=rural) } \\
\hline Urban & 1.201 & 0.382 & $(0.451,1.952)$ & $0.0017 *$ \\
\hline
\end{tabular}

*stands for statistically significant at $5 \%$ level of confidence

The result in Table2 shows that there was significant effect of TB status on CD4 cell count. Hence, the expected number of CD4 cell count of HIV patients who were co-infected with TB was decreased by 2.34 as compared to HIV patients who were free from TB. As age increased by one year, the expected number of CD4 cell count was decreased by 0.128 , given that the other variables constant. The expected number of CD 4 cell count for ambulatory and bedridden HIV patients was decreased by 3.1 and 3.8 respectively as compared to those of working functional status. Similarly, the expected number of CD 4 cell count for medication adherent and dietary adherent HIV patients were increased by 4.6 and 2.6 respectively as compared to those of non-adherent patients, given the other variables constant.

Patients who got social support and those who had cell phone had good improvements in their expected number of CD 4 cell count as compared to their counterparts. Patients' BMI, WHO stages Hemoglobin levels, disclosure level of the disease, opportunistic disease infection and residence area had significant effect on the expected number of CD4 cell count.

The generalized linear mixed effect model (Binary logistic regression model) was implemented for the analysis of the levels of TB status as indicated in Table3. Table3 revealed that the odds of rural HIV patients being infected by TB were 6.3 times higher than those of urban patients. The odds of ambulatory HIV patients being co-infected by TB were greater by $14.6 \%$ as compared to patients at working status, given the other variables constant.

In Table3, it is observed that TB infection was lower for patients whose WHO stages' were 1, 2, and 3 compared to stage 4 , and patients whose religion was orthodox compared to others. Weight and CD4 cell count has a negative relationship with the event of HIV/TB co-infection. In Table3 it is indicated that TB infection was higher for those who were bedridden functional status compared to working status, for patients whose marital status was separated compared to widowed status. In this separate longitudinal 
data analysis intra-class correlation was not investigated. To conduct such correlation between the two responses, joint data analysis was employed. According to the results of longitudinal sub models under separate analysis in Table3, the random effect estimates depicted that intercepts and slopes vary significantly, which suggests that there was significant considerable variation among HIV/AIDS patients from visit to visit.

When the number of CD4 cell count increased, its average effect for odds of a patient being coinfected with TB was around 0.004 times lower for ART treatment [AOR= 0.996; 95\%Cl: 0.994, 0.998]. And the amount of variability among patients due to the effect of time per month in each visit was 0.011 . And the correlation was -0.176 which indicates that there was negative correlation between intercept and slope (when a patient's intercept increase by one unit of standard deviation, that patient's slope decreased by 0.176 standard deviations).Table3 also shows the covariance parameter estimates for separate longitudinal analysis for TB status. 
Table3: Parameter Estimates of TB status, binary logistic regression models data analysis

\begin{tabular}{|c|c|c|c|c|}
\hline Effect & Estimate & Std. Err & $95 \% \mathrm{Cl}$ for $\mathrm{AOR}$ & $\begin{array}{l}\mathrm{p}- \\
\text { Value }\end{array}$ \\
\hline Intercept & 3.136 & 2.011 & $23.01(4.19,212.94)$ & $0.0017 *$ \\
\hline \multicolumn{5}{|c|}{ Residence area(Ref=urban) } \\
\hline Rural & 1.839 & 0.644 & $\begin{array}{l}6.29(1.78 \\
22.25)\end{array}$ & $0.0043^{*}$ \\
\hline \multicolumn{5}{|c|}{ Fun.st. (Ref=working) } \\
\hline Ambulatory & 0.136 & 1.125 & $\begin{array}{l}1.146(0.126 \\
10.423)\end{array}$ & $0.036^{*}$ \\
\hline Bedridden & 3.171 & 1.037 & $\begin{array}{l}\text { 23.831(3.121, } \\
182.00)\end{array}$ & $0.0022^{*}$ \\
\hline \multicolumn{5}{|c|}{ Marital status. (Ref= living without partner) } \\
\hline Living with partner & -0.698 & 1.164 & $\begin{array}{l}0.498(0.051 \\
4.879)\end{array}$ & 0.5486 \\
\hline \multicolumn{5}{|c|}{ WHO stage $($ Ref=st.4) } \\
\hline Stage 1 & -7.896 & 0.728 & $0.04(0.01,0.02)$ & $<0.01^{*}$ \\
\hline Stage 2 & -7.550 & 0.694 & $\begin{array}{l}0.005(0.0001 \\
0.002)\end{array}$ & $<0.01^{*}$ \\
\hline Stage 3 & -3.729 & 0.667 & $\begin{array}{l}0.024(0.006 \\
0.089)\end{array}$ & $<0.01)^{\star}$ \\
\hline Weight & -0.101 & 0.024 & $\begin{array}{l}0.904(0.862 \\
0.946)\end{array}$ & $\begin{array}{l}<0.0001 \\
\star\end{array}$ \\
\hline $\begin{array}{l}\text { CD4 cell } \\
\text { count }\end{array}$ & -0.004 & 0.001 & $\begin{array}{l}0.996(0.994 \\
0.998)\end{array}$ & $<0.0001^{*}$ \\
\hline \multicolumn{5}{|c|}{ Medication adherence $($ Ref. $=$ no $)$} \\
\hline yes & -0.004 & 0.001 & $\begin{array}{l}0.996(0.994 \\
0.998)\end{array}$ & $<0.0001^{*}$ \\
\hline \multicolumn{5}{|c|}{ Dietary adherence(Ref.=no) } \\
\hline yes & -0.004 & 0.001 & $\begin{array}{l}0.996(0.994 \\
0.998)\end{array}$ & $<0.0001^{*}$ \\
\hline
\end{tabular}

To have an appropriate joint model that represents the longitudinally measured of CD 4 count and TB status of the HIV patients, different candidate joint models with different random effect for the joint 
modeling were considered. The AIC and BIC were used as a guideline in selecting covariates for the model. A smaller AIC and BIC values were generally indicates a better model.

In joint modeling of longitudinal outcomes, we have two types of modeling techniques those are marginal model and conditional independency random effects model. Marginal models were not functional in this study because, it did not consider the random parts, where individual effects on the variable of interests can be identified. Table4 revealed that the joint model with random intercept effects with the inclusion of random linear slopes was the best model as compared to random intercept only.

Therefore, the joint model with random intercept and linear slope was considered as an appropriate model. Table4 also shows that the value of fit statistics (AIC and BIC) for all joint models were less than that of the separate models. In this study, both separate and joint models were fitted because in separate analysis one response was considered as linear predictor for the other. Moreover, when we compared the two models (separate and joint), joint model was fitting better the data as compared to the separate model. The result of selected appropriate joint models for the longitudinally measured CD 4 count and TB status of HIV infected patients and indicated in Table4.

The result in Table4 shows that time of follow ups visits, residence area, and functional status, adherence to medication, WHO clinical stages, weight, hemoglobin level and social support were significantly associated with both CD 4 cell count and TB status. In addition, one way interaction terms (time * educational level) was also associated with both outcomes. Unstructured covariance structure was also applied for joint longitudinal data analysis as was done for in separate model analyses.

The random effects for the two outcomes were significantly and negatively associated (Table4). This translates in to a negative correlation between HAART CD4 cell and TB status. This means that increasing the average CD4 cell count per $\mathrm{mm}^{3}$ tends to decrease the chance of being co-infected with TB.

Table4: Parameter estimates of CD4 cell count and TB status using joint model. 


\begin{tabular}{|c|c|c|c|c|c|c|}
\hline \multirow[t]{2}{*}{ Effect } & \multicolumn{3}{|c|}{ TB status } & \multicolumn{3}{|c|}{ CD4 cell count } \\
\hline & Estimate & Std.Err & P-value & Estimate & $\begin{array}{l}\text { Std. } \\
\text { Err }\end{array}$ & P-value \\
\hline Intercept & 6.467 & 2.687 & 0.0162 & 7.857 & 1.863 & $<0.0001$ \\
\hline Time & -0.054 & 0.018 & $0.0025^{\star}$ & 0.205 & 0.010 & $<0.01 *$ \\
\hline Age & -0.025 & 0.031 & $0.026^{\star}$ & -0.099 & 0.022 & $<0.0001^{*}$ \\
\hline \multicolumn{7}{|l|}{ Residence(ref=urban) } \\
\hline Rural & 1.307 & 0.531 & $0.0139 *$ & -0.050 & 0.401 & $0.1013^{\star}$ \\
\hline \multicolumn{7}{|l|}{ Educ.Level (ref=tertiary) } \\
\hline No education & 0.104 & 0.881 & 0.9064 & 1.459 & 0.633 & 0.0212 \\
\hline Primary & -1.387 & 0.901 & 0.1240 & -0.200 & 0.630 & 0.7513 \\
\hline Secondary & 1.701 & 0.952 & 0.0739 & -1.017 & 0.645 & 0.1150 \\
\hline \multicolumn{7}{|l|}{ Func.Stat (ref=working) } \\
\hline Ambulatory & 0.568 & 0.941 & $0.0458^{*}$ & -3.915 & 0.677 & $<0.0001^{*}$ \\
\hline Bedridden & 3.002 & 0.864 & $0.0005^{\star}$ & -4.617 & 0.695 & $<0.0001^{*}$ \\
\hline Other & 1.160 & 0.689 & $0.0925^{\star}$ & -1.637 & 0.516 & $0.0015^{\star}$ \\
\hline \multicolumn{7}{|l|}{ Ols(ref=yes) } \\
\hline No & 0.613 & 0.574 & 0.2849 & 1.542 & 0.429 & 0.0003 \\
\hline \multicolumn{7}{|l|}{$\begin{array}{l}\text { Adherence(ref= non- } \\
\text { adherent) }\end{array}$} \\
\hline Adherent & -1.010 & 0.657 & $0.1046^{\star}$ & 4.379 & 0.427 & $<0.0001^{*}$ \\
\hline WHOst.(ref=stage4) & 0121 & 0600 & 100001* & 2101 & & \\
\hline Stage1 & -8960 & 0671 & - 00001 * & 107 & 0 & \\
\hline Stage2 & & & & & 0.004 & . \\
\hline Stage3 & -4.048 & 0.610 & $<0.0001^{*}$ & 0.030 & 0.372 & $0.0162^{\star}$ \\
\hline Weiaht & -0.146 & 0.032 & $<0.0001^{\star}$ & 0.030 & 0.018 & $<0.0001^{*}$ \\
\hline Hemoglobin & -0.402 & 0.097 & $<0.0001^{\star}$ & 0.587 & 0.073 & $<0.0001^{*}$ \\
\hline BMI(ref=underweight) & -0.528 & 0.433 & 0.2224 & 0.690 & 0.279 & 0.0134 \\
\hline Overweight & -1.286 & 0.233 & 0.1963 & 1.856 & 0.500 & 0.0002 \\
\hline Social sup. $($ ref=yes) & & & & & & \\
\hline
\end{tabular}




\begin{tabular}{|c|c|c|c|c|c|c|}
\hline \multirow{2}{*}{$\begin{array}{l}\text { No } \\
\text { Time*educational } \\
\text { level(Ref.=Tertiary) }\end{array}$} & 0.531 & 0.488 & $0.0260 *$ & -1.100 & 0.371 & $0.0033^{\star}$ \\
\hline & & & & & & \\
\hline Time*no education & 0.155 & 0.031 & $<0.0001^{*}$ & 0.190 & 0.016 & $<0.0001 *$ \\
\hline Timotnrimany & 0.144 & 0.042 & $0.0007 *$ & 0.246 & 0.019 & $<0.0001^{*}$ \\
\hline Time*secondary & 0.003 & 0.043 & $0.0455^{\star}$ & 0.203 & 0.021 & $<0.0001^{*}$ \\
\hline
\end{tabular}

According to the results of longitudinal model under joint analysis in Table4, the random effect estimates indicated that intercepts and slopes vary significantly, which suggests that there was significant considerable variation among HIV/AIDS patients from visit to visit.

As visiting times of patients to hospitals for treatment increased by one unit, the odds of being coinfected with TB was decreased by 0.05 and the expected number of CD 4 cell count was increased by 0.2 given the other variables constant.

As weight of patients increased by one unit, the odds of being co-infected with TB was decreased by 1.3 and the expected number of CD4 cell count was increased by 0.03 given the other variables constant. As patient's age increased by one year the expected number of CD 4 cell count was decreased by 0.099 and the odds of being co-infected with TB was increased by 0.025 controlling other variables constant.

The expected number of CD 4 cell count for patients whose functional status were ambulatory, was decreased by 3.9 as compared to those patients whose functional status was working status. But, the odds of an ambulatory patients being co-infected with TB was increased by 0.6 as compared to those patients at working status. Similarly, the expected number of CD 4 cell count for bedridden patients was decreased by 4.6 as compared to patients with working status and the odds of bedridden patients being co-infected with TB was increased by 3 as compared to patients with working status.

Patients' adherence status was also another important variable for CD4 cell count and TB status and the result showed that, the expected number of CD 4 cell count for adherent patients was 4.4 times that of non-adherent patients and the odds of being co-infected with TB for adherent patients was decreased by 1.0 given the other variables constant..

The expected number of CD 4 cell count for patients who did not get social support was decreased by 1.1 as compared to those who got social support but the odds of being co-infected with TB for patients who did not get social support was increased by 0.5 controlling the other variables constant. 
As hemoglobin level of patients increased by one unit, the expected number of CD4 cell count of HIV patients increased by 0.59 cell per/mm3 but the odds of being co-infected with TB for such patients decreased by 0.4 keeping the other variables constant.

The expected number of CD 4 cell count for patients whose WHO of stage 1 was greater by 2.5 cells per $\mathrm{mm} 3$ as compared to stage 4 but the odds of being co-infected with TB for WHO stage 1 patients was decreased by 9.1 as compared to stage 4 . Similarly, the expected number of CD 4 cell count of WHO stage2 patients was greater by 1.1 and the odds of being co-infected with TB for WHO stage2 patients was decreased by 8,9 as compared to those of patient whose WHO stages were stage4 given the other variables constant..

In Table4, it is also indicated that the expected number of CD4 cell count for rural patients was decreased by 0.05 as compared to urban patients but the odds of being co-infected with TB for rural patients was increased by 1.3 as compared to urban patients given the other variables constant.

The interaction effect in Table4 indicates that, as visiting time of a patient increased by one unit, the expected number of CD 4 cell count for non-educated patients was decreased by 0.2 but the odds of being co-infected with TB for such patients was increased by 0.15 as compared to tertiary educated patients, keeping the other variables constant. Similarly, as visiting time of patients increased by one unit, the expected number of CD 4 cell count for primary educated patients was decreased by 0.24 cells per mm3 and the odds of being co-infected with TB was increased by 0.14 as compared to tertiary educated patients keeping the other variables constant.

\section{Discussion}

In this study, separate and joint models were explored. Joint models fitted the data very well as compared to separate models. This result was also consistent with one of the previous research, [14].

Results from this study demonstrated that patients under first, second and third WHO clinical stages have more expected number of CD4 cell count as compared to patients with the fourth stage but the odds of being co-infected with TB was decreased for patients with WHO stages of 1, 2 and 3 as compared to stage4. This indicates that the two responses are negatively correlated to each other. This result was supported by one of the previous investigations[15]. The potential reason for this might be, patients at these stages, the CD4 cells may not be destroyed by the disease as compared stage 4 and such patients may not loss their weight as compared to stage4 [16].

Naturally, as age increased or being older and older, the expected number of CD 4 cell count decreased from time to time. The odds of being confection of such aged patients increased and such result is consistent with another study[17].

Patients who were adhered their prescribed medication had more CD4 cell count than who did not adhere. And also weight and hemoglobin level has a positive relationship with CD4 count that is for a unit change 
of weight or hemoglobin level, expected number of CD4 cell count also increased. This might be due to the fact that patients who feed low dietary diversity of food linked directly to weight and hemoglobin. This result was also conformed to the result obtained by previous research [18].

Education significantly affected the level of CD4 cell count and the odds of being co-infected with TB. Hence, more educated patients have better understanding about adherence to prescribed medication and this further leads to better CD 4 cell count as compared to uneducated patients. Such educated patients with better CD4 cell count had smaller odds of being co-infected with TB. The result obtained in current research is consistent with one of the previous investigation [19].

HIV patients who got social support from community around them have better CD 4 cell count and such patients have low odds of being co-infected with TB. The potential reason for this may be the fact that such patients might have good medication as well as food adherence and this leads for more expected number of CD 4 cell count and less probable of being co-infected with TB [20].

Rural area resident patients are more likely to be co-infected by HIV/TB as compared to urban residents. This result is consistent with one of a previously conducted research[21]. This might be due to the fact that in rural areas, the patients may faced with lack of balanced diet and proper adherence to medication because of limited accessibility of ART clinic settings or health facilities as compared to urban and low level of patients' awareness about the treatment. This indicates that the exposure of status of TB on HIV patients were high in rural area [22].

\section{Conclusion}

In conclusion, when the two longitudinal responses are correlated, valid inferences can be made through the use of a joint modeling approach. In the longitudinal sub-model of CD 4 cell count, the predictors: Age, functional status, WHO clinical stage, educational level, opportunistic infectious disease, Body mass index, adherence, weight and hemoglobin and visiting times were statistically significant at $5 \%$ level of confidence.

For the longitudinal sub-model of TB status, residence area, religion, functional status, marital status, WHO stages, and weight were significant at $5 \%$ level of confidence.

In joint analysis, age, opportunistic infection disease, adherence, body mass index and social supports were significantly associated with CD4 cell count. And only residence has a significant association with TB status. In addition one way interaction terms (time * educational level) was also associated with both outcomes.

The results of both the separate and joint analyses are consistent. However, a joint analysis was more adequate and efficient inferences can be made (using AIC and BIC). This means that joint modeling can benefit the analyses of both longitudinal biomarkers. 
Having lower CD4 cells count, lower weight, late WHO clinical stages, being non-adherent, opportunity infection disease, lower hemoglobin, being ambulatory and bedridden are associated with higher risk of co-infection of HIV/TB and are indicators of the progression of the disease. Therefore, patients should be informed about the need for early diagnosis of HIV infection and starting treatment early is very important as per the recent WHO 'treat all' recommendation.

Integrated interventions for HAART program enhanced treatment access with improved health quality and food security. Supporting healthcare providers, development of social policies, a cooperation between various agencies are required to facilitate to ART and retention in care by HAART. It is also recommended that further studies including viral load might provide additional information for current investigation.

\section{Abbreviations}

HAART = Highly Active Retroviral Therapy, AOR = Adjusted Odds Ratios, $\mathrm{Cl}=$ Confidence Interval, $\mathrm{BMI}=$ Body Mass index, TB= Tuberculosis, PLWHIV= People living with HIV.

\section{Declarations}

Ethical approval and consent for participate: The data used in current investigation was collected previously by the health staff for treatment purpose/for diagnosis HIV/AIDS and to start ART. To use this previously collected data, Ethical approval certificate had been obtained from two committees namely Bahir Dar University Ethical approval committee, Bahir Dar University, Ethiopia with reference number: RCS/1412/2011. In data collection, there was no written or verbal consent from participants. The reason was, investigators didn't get participants rather, and secondary data was obtained in patients' chart. The Ethical approval committee approved for the use of this secondary data for current investigation.

Consent for publication: This manuscript has not been published elsewhere and is not under consideration by any other journal. Both authors approved the final manuscript and agreed with its submission. We agreed about authorship and the order of authors for this manuscript.

Availability of data and materials: Authors confirmed that the data used for this research is available at corresponding author.

Competing interests. There is no financial and non-financial competing interest between authors or between authors and institutions.

\section{Funding: Not applicable}

Authors' contributions: SB wrote the proposal, develop data collection format, supervise the data collection process, analyzed and interpreted the data. AST participated in design and data analysis and critically read the manuscript and amend constructive comments for the betterment of the manuscript 
applying his rich experience. Both authors contributed equally on manuscript preparation and approved the manuscript to be submitted for publication.

Acknowledgement: Authors acknowledged the Amhara Region Health Research \& Laboratory Center at Felege Hiwot Teaching and Specialized Hospital, Ethiopia, for the data they supplied for the success of this research.

\section{References}

1. Initiative, S.T. and W.H. Organization, The Stop TB Partnership annual report 2006: a portrait of progress, 2007, Geneva: World Health Organization.

2. Sharma, S., A. Mohan, and T. Kadhiravan, HIV-TB co-infection: epidemiology, diagnosis \& management. Indian J Med Res, 2005. 121(4): p. 550-567.

3. World Health Organization, Global tuberculosis report. 2012.

4. Unaids, A., by the numbers. 2016, 2017.

5. Wang, H., et al., Estimates of global, regional, and national incidence, prevalence, and mortality of HIV, 1980-2015: the Global Burden of Disease Study 2015. The lancet HIV, 2016. 3(8): p. e361-e387.

6. Sotgiu, G., et al., Epidemiology and clinical management of XDR-TB: a systematic review by TBNET. European Respiratory Journal, 2009. 33(4): p. 871-881.

7. Deribew, A., et al., Tuberculosis and HIV co-infection: its impact on quality of life. Health and quality of life outcomes, 2009. 7(1): p. 105.

8. Organization, W.H., Global tuberculosis control: surveillance, planning, financing: WHO report 2008. Vol. 393. 2008: World Health Organization.

9. Demissie, M., B. Lindtjørn, and B. Tegbaru, Human Immunodeficiency virus (HIV) infection in tuberculosis patients in Addis Ababa. Ethiopian Journal of Health Development, 2000. 14(3).

10. Ahmed Yassin, M., et al., HIV and tuberculosis coinfection in the southern region of Ethiopia: a prospective epidemiological study. Scandinavian journal of infectious diseases, 2004. 36(9): p. 670673.

11. Adams, M. and A. Luguterah, Longitudinal analysis of change in CD4+ cell counts of HIV-1 patients on antiretroviral therapy (ART) in the Builsa district hospital. European Scientific Journal, ESJ, 2013. 9(33).

12. Laird, N.M. and J.H. Ware, Random-effects models for longitudinal data. Biometrics, 1982: p. 963974.

13. Thijs, H., G. Molenberghs, and G. Verbeke, The milk protein trial: influence analysis of the dropout process. Biometrical Journal: Journal of Mathematical Methods in Biosciences, 2000. 42(5): p. 617646.

14. Fujiwara, P., P. Clevenbergh, and R. Dlodlo, Management of adults living with HIV/AIDS in low-income, high-burden settings, with special reference to persons with tuberculosis [State of the Art Series. HIV 
infection in low-income, high-burden settings, Edited by JF Murray. Number 5 in the series]. The International Journal of Tuberculosis and Lung Disease, 2005. 9(9): p. 946-958.

15. Malta, M., et al., Adherence to antiretroviral therapy among HIV-infected drug users: a meta-analysis. AIDS and Behavior, 2010. 14(4): p. 731-747.

16. Manyara, J., Factors associated with delayed antiretroviral therapy initiation among Tuberculosis/Human Immunodeficiency Virus co-infected patients in Lupane district, 2015. 2016.

17. Bello, E.J.M., et al., Predictors of virologic failure in HIV/AIDS patients treated with highly active antiretroviral therapy in Brasília, Brazil during 2002-2008. Drug Target Insights, 2011. 5: p. DTI. S7527.

18. Katubulushi, M., et al., Slow decline in CD4 cell count in a cohort of HIV-infected adults living in Lusaka, Zambia. Aids, 2005. 19(1): p. 102-103.

19. Katlama, C., et al., Efficacy and safety of TMC114/ritonavir in treatment-experienced HIV patients: 24week results of POWER 1. Aids, 2007. 21(4): p. 395-402.

20. Worodria, W., et al., Incidence and predictors of mortality and the effect of tuberculosis immune reconstitution inflammatory syndrome in a cohort of TB/HIV patients commencing antiretroviral therapy. JAIDS Journal of Acquired Immune Deficiency Syndromes, 2011. 58(1): p. 32-37.

21. Montales, M.T., et al., HIV-associated TB syndemic: a growing clinical challenge worldwide. Frontiers in public health, 2015. 3: p. 281.

22. Silva, D.I., et al., Predictors of Mortality among Individuals with Tuberculosis and Human Immunodeficiency Virus Coinfection at a Reference Center in Southeastern Brazil: A Retrospective Cohort Study. Journal of Young Pharmacists, 2018. 10(4). 